\title{
Evaluating Models Of The Relationship Between Accounting Profitability Measures And Internal Rate Of Return
}

Steven R. Fritsche, Howard University, USA

Michael T. Dugan, University of Alabama, USA

\begin{abstract}
Researchers have investigated the relationship between the internal rate of return (IRR) and accounting-based profitability measures using analytical and indirect empirical methodologies. The current study employs computer simulation to complement the other two methodologies and corroborate their results. The results indicate that the accounting rate of return (ARR) and the conditional estimate of internal rate of return (CIRR) are strongly associated with IRR; however, the length of the estimation period and formulation used for CIRR appear to affect its relationship to IRR. ARR's relationship to IRR appears to be unaffected by the length of the estimation period.
\end{abstract}

\section{INTRODUCTION}

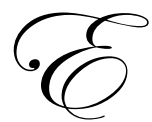

valuating the profitability of economic entities remains a frustrating experience for those individuals who engage in the activity. The inability to observe true economic or internal rates of return (IRR) leaves interested parties with little choice but to resort to accounting-based alternatives, such as the accounting rate of return $(A R R)$ and the conditional estimate of internal rate of return $(C I R R)$. However, the adequacy of these surrogates for economic returns is difficult to determine when the unobservable IRR cannot be used as a benchmark. This apparent impasse has resulted in an extant research literature based on analytical and indirect empirical methodologies.

The findings of analytical research have provided a number of important insights into the relationship between accounting-based profitability measures and IRR. For example, analytical research has found that ARR exhibits sensitivity to accounting valuation bases and allocation methods, inflation, cash flow patterns, real growth rates, and length of asset lives in some models. ${ }^{1}$ Additionally, although Salamon $(1982,1985)$ explicitly incorporated several of these factors when he developed the CIRR from Ijiri's $(1978,1979,1980)$ cash recovery rate $(C R R)$, various analytical models indicate that CIRR's usefulness is limited, as well. Its computation relies on assumptions of a fixed real investment growth rate (Brief 1985; Stark 1989), a fixed cash flow parameter (Brief 1985; Griner and Stark 1991), assumed project lives (Brief 1985; Hubbard and Jensen 1991), and a definition of cash from operations based on working capital (Lee and Stark 1987; Griner and Stark 1988). By describing in detail how these factors alter the relationships between accounting-based profitability measures and $I R R$, the analytical results also have provided a variety of questions that could or already have become the focus of direct or indirect empirical investigations. Empirical validation is an important next step in the effort to understand the strengths and weaknesses of alternative profitability measures.

Although our understanding of the relationship between accounting-based profitability measures and IRR has benefited greatly from analytical research, the progress of researchers interested in uncovering empirical support for the findings of the analytical research has been limited by experimental design issues. In particular, researchers have had to design rigorous investigations using observable variables that support plausible inferences about the association between accounting-based profitability measures and IRR. Generally, such investigations begin by asserting or acknowledging a relationship between an observable variable, such as systematic risk (Fritsche and Dugan 1996) or the ratio of entity cash flows to capital expenditures (Griner and Stark 1988), and IRR. The 
observable variable then becomes a surrogate for $I R R$ in the empirical analysis. The empirical investigation can then focus on the relationship between the observable variable and accounting profitability measures, with an emphasis on the impact of one or more of the factors identified above as a potential confounding factor.

The indirect empirical approach described above also has inherent challenges. First, it adds an additional source of error to an empirical study. In addition to the normal sources of experimental error (e.g., random variability and omitted variables), the researcher must be concerned about the error in the relationship between the IRR surrogate and IRR. Second, as Dugan and Shriver (1988) noted, when the dependent variable in a study is "determined" by the researcher (that is, where the study does not contain an environmentally determined criterion variable), care should be exercised when reporting or interpreting the results of the investigation. Put another way, it is important to remember that an $I R R$ surrogate has been used, rather than IRR itself. For example, in discussing Salamon's (1988) evaluation of ARR by observing its behavior in relation to CIRR, Peasnell (1996) cautioned that the conclusions drawn by Salamon depend on the suitability of $C I R R$ for use as a criterion variable.

In light of the limitations of analytical and indirect empirical research methodologies, the current study offers yet another approach - computer simulation. This approach is offered as a complement to, not a substitute for, other methodologies. The perspective offered is that a reasonable strategy for researchers interested in developing or evaluating accounting-based profitability measures involves addressing research questions with as many appropriate methodologies as is practicable. In this way, interested parties may have greater confidence in those results that are consistently obtained through multiple methods. Of course, when alternative methods produce conflicting results, caution is appropriate. Additionally, by using computer simulation, the current study is able to produce a measure of IRR that could not be derived from published financial accounting information.

As an illustration of the potential offered by computer simulation, some empirical results of two published indirect empirical studies were replicated. In their study, Griner and Stark (1988) presented analytical results to demonstrate a relationship between the ratio of entity cash flows to investment expenditures and IRR. On this basis, they used the ratio as a surrogate for $I R R$ and found strong evidence indicating that linear relationships existed between their IRR surrogate and several formulations of CIRR. Salamon (1988) found significant differences in the median values of $A R R$ and $C I R R$ and concluded that $A R R$ differed from IRR. He then developed analytical models that indicated $A R R$ and $I R R$ can be expected to be on the same side of investment growth. Again using $C I R R$ as a surrogate for $I R R$, Salamon presented regression and other evidence that supported the implications of his analytical models. Both of these studies employ indirect empirical approaches and rely on data that can be produced by a computer simulation.

The description of the current study is presented as follows. In the next section, the computer simulation is described in detail. Thereafter, the third section describes the variables used and the hypotheses tested. The fourth section sets out the research hypotheses. In the fifth section, the statistical tests and results are presented. The paper concludes with a summary.

\section{SIMULATION METHODOLOGY}

The data used in this study are based on the financial statement information of simulated firms. A Monte Carlo technique simulated the operations of a sample of firms for a total of 47 periods. During each of the periods, the simulated firms engaged in the activities typical of real firms. These activities included selling products or services, acquiring inventory (except in the case of service firms), incurring operating expenses, arranging financing (by borrowing), and investing in long-term assets. All of these activities took place in the economic environment described below.

Although every effort was made in the simulation process to capture the essential characteristics of real firms and the environments in which they operate, the results of the current study must be considered similar in some respects to those of laboratory experiments. Greater control over experimental variables and the improvements in measurement precision were obtained by limiting the ability to draw inferences about actual firms based on the results of the current study (Kerlinger 1980; Rivett 1980). This scenario reflects the classic trade-off between internal validity and external validity inherent in such situations. 
The economic environment of the simulation program incorporated the following structure. The growth rate in quantity of product or services demanded in a given period was selected from a uniform distribution that ranged from ten percent above to ten percent below its expected value. The quantity of inventory purchased in the current period was the previous period's quantity demanded, less any units remaining in inventory at the beginning of the current period. Thus, the quantity of units of inventory sold in a given period was equal to the smaller of the quantity demanded in the current period, or the quantity demanded in the previous period.

Three features of the economic environment were determined exogenously because the processes needed to generate them are too complex to incorporate into the simulation program. First, the simulation program used United States Gross Domestic Product Implicit Price Deflators from 1949 through 1995 to represent inflation in the simulated environment. These inflation rates affected selling prices, input prices, operating costs, and the cost of plant asset purchases. Second, the complexity of simulating the market processes needed to derive changes in product demand resulted in the need to establish expected growth rates for product demand exogenously. Each firm was simulated using assumed expected growth rates for quantity of product or services demanded of $-.05,0$, and .05 . These growth rates also affected operating costs and the cost of plant asset purchases. Finally, the interest rates used to determine the cost of debt were the bank prime loan rates on short-term business loans as reported by the Federal Reserve Bank in St. Louis from 1949 through 1995.

Industry average data from Robert Morris Associates (1995) defined the initial financial position and operating characteristics of each firm. The initial composition of each firm's balance sheet resulted from selecting an arbitrary value for total assets (1,000 currency units) and applying the percentages from the composite balance sheet data for the industry to this total. For manufacturing industries, the initial selling price per unit of output was 10 currency units, and applying 1 minus the composite gross margin percentage for the industry produced the initial cost per unit. Using median values of financial statement ratios for the industry, the simulation determined the following operating characteristics: (1) the percentage of inventory purchases paid within the year of purchase, (2) the percentage of sales revenues collected in the year of sale, (3) the percentage of operating and interest expenses paid within the year incurred, (4) the percentage of long-term debt maturing in the following period, (5) the percentage of total assets maintained in the form of cash, and (6) the average depreciable life of plant and equipment. Tables 1 and 2 describe the determination of operating characteristics in greater detail. Each firm's accounts were updated to reflect each period's transactions in accordance with basic double-entry accounting procedures.

The industry averages used to create the simulated firms were taken from the two-digit SIC classifications used by Salamon (1988). This approach produced a sample of 167 sets of industry averages for four-digit SIC classifications within the two-digit classifications. Using firms with Salamon's industry groups should facilitate comparison of the results of this study with those reported by Salamon, thereby allowing a clearer interpretation of both sets of results.

Table 1

Financial Statement Ratios Used in Computer Simulation

\begin{tabular}{lc}
\hline \multicolumn{1}{c}{ Financial Statement Ratio } & $\begin{array}{c}\text { Label Used } \\
\text { in Formulae }\end{array}$ \\
\hline Cash \& Equivalents / Total Assets * 100 & $\mathrm{A} 1$ \\
Trade Receivables--(net) / Total Assets * 100 & $\mathrm{A} 2$ \\
Total Current Assets / Total Assets * 100 & $\mathrm{A} 3$ \\
Notes Payable--Short-Term / Total Assets *100 & $\mathrm{A} 4$ \\
Current Maturities of Long-Term Debt / Total Assets *100 & $\mathrm{A} 5$ \\
Trade Payables / Total Assets * 100 & $\mathrm{A} 6$ \\
Total Current Liabilities / Total Assets * 100 & $\mathrm{A} 7$ \\
Net Worth / Total Assets * 100 & $\mathrm{A} 8$ \\
Gross Profit / Sales * 100 & $\mathrm{A} 9$ \\
Operating Expenses / Sales * 100 & $\mathrm{A} 10$ \\
Sales / Receivables & $\mathrm{A} 12$ \\
Cost of Sales / Payables & $\mathrm{A} 14$ \\
Sales / Total Assets & $\mathrm{A} 16$ \\
Depreciation, Depletion, \& Amortization / Sales * 100 & $\mathrm{A} 17$ \\
\hline
\end{tabular}


Table 2

Formulae Used to Calculate Simulation Parameters and Opening Balance Sheets for Simulated Firms

\begin{tabular}{|c|c|}
\hline Value Calculated & Formula \\
\hline Cash & Total Assets * A1 / 100 \\
\hline Trade Receivables & Total Assets * A2 / 100 \\
\hline Inventory (Cost) & (Total Assets * A3 / 100) - Cash - Trade Receivables \\
\hline Inventory (Units) & Inventory $($ Cost $) /($ Selling Price $*(1-(A 9 / 100)))$ \\
\hline Gross Fixed Assets & (Total Assets - Cash - Trade Receivables - Inventory $($ Cost $)) * 2$ \\
\hline Accumulated Depreciation & Gross Fixed Assets / 2 \\
\hline Fixed Asset Purchases (Year 0) & $(\mathrm{A} 17 / 100) *($ Total Assets $*$ A16 / 100) \\
\hline Short-Term Notes Payable & Total Assets * A4 / 100 \\
\hline Current Maturities of Long-Term Debt & Total Assets * A5 / 100 \\
\hline Trade Payables & Total Assets * A6/ 100 \\
\hline Accrued Liabilities & $\begin{array}{l}\text { (Total Assets * A7 / 100) - Short-Term Notes Payable - Current } \\
\text { Maturities of Long-Term Debt - Trade Payables }\end{array}$ \\
\hline Stockholders' Equity & Total Assets * A8 / 100 \\
\hline Long-Term Debt & $\begin{array}{l}\text { Total Assets - Short-Term Notes Payable - Current Maturities } \\
\text { of Long-Term Debt - Trade Payables - Accrued Liabilities - } \\
\text { Stockholders' Equity }\end{array}$ \\
\hline Operating Expenses (Year 0) & $(\mathrm{A} 10 / 100) *($ Total Assets $*$ A16 / 100) \\
\hline Unit Cost of Inventory (Year 0) & Selling Price $*(1-($ A9 / 100) $)$ \\
\hline Expected Unit Demand (Year 0) & Total Assets * A16 / Selling Price \\
\hline Portion of Purchases Paid for in Year of Purchase & $1-(1 / \mathrm{A} 14)$ \\
\hline Portion of Sales Collected in Year of Sale & $1-(1 / \mathrm{A} 12)$ \\
\hline Portion of Operating Expenses Paid for in Year of Incurrence & 1 - (Accrued Liabilities / Operating Expenses (Year 0)) \\
\hline Portion of Long-Term Debt Maturing in Next Period & Current Maturities of Long-Term Debt / Long-Term Debt \\
\hline Portion of Total Assets Maintained in the Form of Cash & Cash / Total Assets \\
\hline
\end{tabular}

Analytical research investigating the relationship between $A R R$ and IRR has consistently identified the firm's depreciation method and inventory cost flow assumption as factors contributing to the observed differences between the two rates. For this reason, each firm was simulated using both LIFO and FIFO inventory cost flow assumptions. To further support comparing the results of this study with those of Salamon (1988), each member industry of the two-digit SIC classes was randomly assigned to either the straight-line or sum-of-the-years'-digits groups, roughly in proportion to the observed usage patterns reported by Salamon.

Finally, to assess the sensitivity of the results to the length of the estimation period used to calculate variables, three different estimation periods were used: 5, 10, and 15 periods. These estimation periods were based on the last 5,10 , and 15 periods of the 47 periods simulated for each firm. This approach left a "warm-up" phase of at least 32 operating periods. The "warm-up" phase allowed the simulated firm's operating and financial results to stabilize before data accumulation began. As a result of the factors discussed above, the sample for each of the three estimation periods (5, 10, and 15 periods) contains 1,002 observations. This number results from the following: 167 sets of industry averages x 2 inventory cost flow assumptions (FIFO and LIFO) x 3 expected growth rates (-.05, 0.0, and .05).

\section{VARIABLE DEFINITIONS AND HYPOTHESIS DEVELOPMENT}

To replicate the studies by Salamon (1988) and Griner and Stark (1988), the current study required measures of CIRR, ARR, the ratio of entity cash flows to capital investment, and growth of investment. Each of these variables is described in turn before presenting the measure of $I R R$ that was used to corroborate and extend the results of the two earlier studies.

A substantial literature has developed around the development and testing of CIRR. This profitability measure is a complex elaboration of a capital budgeting tool developed by Ijiri $(1978,1979,1980)$. Ijiri suggested the use of a cash recovery rate $(C R R)$ to measure investment performance. His cash recovery rate was based on the reciprocal of the traditional payback period. Ijiri demonstrated that under certain steady state conditions, the $C R R$ 
was related to a return measure that converged to the firm's IRR. Although Ijiri's definition of $C R R$ was based on working capital, Lee and Stark (1987) and Griner and Stark (1988) suggested that a cash flow definition is more consistent with the capital budgeting environment from which $C R R$ developed. Thus, the current study defines $C R R$ in the following way:

$$
C R R_{i t}=\frac{N C F O_{i t}}{G P A_{i t}}
$$

where $N C F O$ is net cash flow from operations, and GPA is the average accounting value (cost) of plant assets during the period.

Salamon (1982) extended Ijiri's work to develop a more complete representation of the relationship between $C R R$ and an estimate of the firm's real internal rate of return that Salamon described as cirr. The relationship derived by Salamon (1982) is as follows:

$$
C R R=\left[\frac{(1-p g) p^{n} g^{n}}{1-p^{n} g^{n}}\right] \cdot\left[\frac{g^{n}-b^{n}}{g^{n}(g-b)}\right] \cdot\left[\frac{r^{n}(r-b)}{r^{n}-b^{n}}\right]
$$

where $r$ is 1 plus cirr, $p$ is 1 plus the inflation rate, $g$ is 1 plus the growth rate in investment (gross assets), $n$ is the useful life of the firm's composite project, and $b$ is an assumed cash flow parameter.

Several features of Salamon's model require additional comment. First, because (2) explicitly incorporates price level changes, the resulting cirr is a conditional estimate of the firm's real internal rate of return.

Second, growth rate in investment is defined as the logarithm of the ratio of the price level adjusted amount of gross plant assets at the end of the estimation period divided by the price level adjusted amount of gross plant assets at the beginning of the estimation period. This definition also was used by Salamon $(1982,1985,1988)$ and Griner and Stark (1988).

Third, the current study calculated the life of the firm's composite project, $n$, by first dividing gross property, plant, and equipment by depreciation expense for each year included in the estimation period, and then calculating the average of those annual estimates when the firm's depreciation expense was determined using the straight-line method. When the simulated firms used the sum-of-the-years'-digits depreciation method, $n$ was calculated using the sum-of-the-years'-digits approach suggested by Buijink and Jegers (1989).

Finally, the calculation of cirr is conditioned on the assumed value of $b$, the cash flow parameter. If $b$ is greater than 1, the cash flows of the firm's composite project increase over its life, if $b$ is less than 1, the cash flows of the firm's composite project decrease over its life, and if $b$ equals 1 , the cash flows remain level. The current study addressed this issue by using three different values for $b$ to assess the sensitivity of the results to the assumed cash flow parameter. Table 3 indicates the values used for $b$ and the label assigned to the resulting values of $c i r r .{ }^{2}$

Table 3

Values Used for $b$ to Compute Alternative Formulations of cirr

\begin{tabular}{cc}
\hline $\begin{array}{c}\text { Values Used } \\
\text { for } \boldsymbol{b}\end{array}$ & $\begin{array}{c}\text { Label Used } \\
\text { for } \text { cirr }\end{array}$ \\
\hline .8 & $\operatorname{cirr}_{1}$ \\
1.0 & $\operatorname{cirr}_{2}$ \\
1.2 & $\operatorname{cirr}_{3}$ \\
\hline
\end{tabular}


A number of definitions have been developed for $A R R$. The vast majority of these variations can be classified as being entity-based (i.e., related to return on assets) or equity-based (i.e., related to return on equity). Although both entity and equity versions of the definition may be appropriate performance measures for particular decision contexts, an entity version was selected for the current study. ${ }^{3}$ CIRR attempts to measure the performance of a composite project made of the productive assets used by a firm. Thus, comparisons of CIRR with an entitybased version of $A R R$ seemed more appropriate because each profitability measure is designed to measure management's ability to make appropriate investments in productive assets. The first step in calculating the version of $A R R$ used in the current study is as follows:

$$
A R R_{i t}=\frac{E B I T_{i t}}{T A_{i t}}
$$

where EBIT is earnings before interest and taxes determined on an accrual basis, and $T A$ is the value reported for total assets in the balance sheet as of the end of the previous period.

Although this definition is consistent with measuring entity performance, its components are measured using current period dollars. That is, (3) is a nominal measure of ARR. To arrive at an approximation of a real measure of $A R R$, labeled arr, the current study follows the suggestion by Beaver (1979) and includes the following conversion first described by Fisher (1930):

$\operatorname{arr}_{i t}=\frac{A R R_{i t}}{\left(1+\rho_{t}\right)}$

where $\rho$ is the inflation rate in the current period. This approximation approach avoids the complexity of a complete restatement of all items included in the income statement and balance sheet to common dollar amounts.

Griner and Stark (1988) developed an analytical model to show that the ratio of entity cash flows to capital investment is related to the firm's IRR. In the context of the simulation program used in the current study, their ratio is defined as follows:

$\frac{\left[\frac{N C F O_{i t}}{\prod_{j=1}^{t}\left(1+\rho_{j}\right)}\right]}{\left[\frac{G P A_{i t}^{+}}{\prod_{j=1}^{t}\left(1+\rho_{j}\right)}\right]}=\frac{n c f o_{i t}}{g P a_{i t}^{+}}$

where $n c f o$ is net cash flow from operations, discounted to time 0 dollars (i.e., currency units as of the beginning of the simulation), and $\mathrm{gpa}^{+}$is the increase in gross plant assets in the current period, also discounted to time 0 dollars. Again, to remain consistent with the definition of cirr described above, the components of the ratio are based on real magnitudes.

Both Salamon (1988) and Griner and Stark (1988) used a measure of growth in their analyses. The current study employs the definition of growth described above in connection with the calculation of cirr. Again, this definition is consistent with previous work by Salamon $(1982,1985,1988)$ and Griner and Stark (1988).

As a way of testing the validity of the results reported by Salamon (1988) and Griner and Stark (1988), the current study employed a direct calculation of each firm's real internal rate of return, irr, for the sample periods 
examined. To aid in the presentation of the research hypotheses later in the paper, the label used for this variable will be roi. The definition requires that the firm's cumulative investment in assets, CUMINV, at the beginning and end of the time interval be known and that the values of this variable be expressed in real magnitudes. The current study defines $C U M I N V$ as follows:

$$
C U M I N V_{i t}=C U M I N V_{i t-1}+\frac{G P A_{i t}^{+}}{\prod_{j=1}^{t}\left(1+\rho_{j}\right)}-\frac{G P A_{i t-n}^{-}}{\prod_{j=1}^{t-n}\left(1+\rho_{j}\right)}=C U M I N V_{i t-1}+g p a_{i t}^{+}-g p a_{i t}^{-}
$$

where $\mathrm{gpa}^{-}$is the decrease in gross plant assets in the current period, discounted to time 0 dollars. The simulation did not incorporate the market processes necessary to accommodate disposal of plant assets by sale. Therefore, the cost of plant assets and the related accumulated depreciation were removed from the firm's accounts at the end of the assets' lives. This approach to plant asset disposals is equivalent to the treatment given to assets that have been discarded. Values of $C U M I N V$ at the beginning and end of the sample periods in the study are used as beginning and ending economic values of the firm's composite project. Put another way, the definition of real IRR, labeled roi, used in the current study relies on the assumed correspondence of the cumulative investment in the firm's assets, discounted to time 0 dollars, to a market valuation, in real magnitudes, of those same assets. ${ }^{4}$ The formula used to calculate $r o i$ is as follows:

$$
0=C U M I N V_{i 0}-\left[\sum_{t=1}^{n^{*}} \frac{\frac{N C F O_{i t}-G P A_{i t}^{+}}{\prod_{j=1}^{t}\left(1+\rho_{j}\right)}}{\left(1+\text { roi }_{i}\right)^{t}}\right]+\frac{C U M I N V_{i n^{*}}}{\left(1+r o i_{i}\right)^{t}}
$$

In this formula, roi is calculated through an iterative process that terminates when a net present value of 0 is reached.

The formula used to calculate roi reflects the premise that most parties interested in evaluating the performance of a firm will be interested in a finite time interval, rather than the firm's entire life. This premise is based on the impossibility of calculating profit rates for corporate entities with indefinite lives and the finite time horizons used by investors and other interested parties.

Having defined the necessary variables, the research questions addressed by the current study may be described. In the next section, these questions are expressed in the form of hypotheses that can be tested empirically.

\section{HYPOTHESES}

The current study began by considering whether a measure of central tendency for $A R R$ differed from that of IRR. Using CIRR as a surrogate for IRR, Salamon (1988) investigated the strength of ARR's association with $I R R$. In adopting this focus, he emphasized the inferences that may be drawn from an observable surrogate, even if that surrogate contains systematic error. By comparing the median values of arr and cirr with those of roi, the current study provides the additional insight about the existence of bias in the two accounting-based profitability measures. Additionally, the use of medians avoided questions about the normality of the variables' distributions and also provided a more conservative test for the existence of differences. Let $\mathrm{M}$ represent the median value of the variable in question. The first sets of hypotheses investigated are as follows: 
$\mathrm{H}_{\mathrm{o}} 1 \mathrm{~A}: \mathrm{M}_{a r r}=\mathrm{M}_{r o i}$

and

$$
\mathrm{H}_{\mathrm{a}} 1 \mathrm{~A}: \mathrm{M}_{a r r} \neq \mathrm{M}_{r o i}
$$

$$
\begin{aligned}
& \mathrm{H}_{\mathrm{o}} 1 \mathrm{~B}: \mathrm{M}_{\text {cirr }}=\mathrm{M}_{r o i} \\
& \mathrm{H}_{\mathrm{a}} 1 \mathrm{~B}: \mathrm{M}_{\text {cirr }} \neq \mathrm{M}_{r o i}
\end{aligned}
$$

The relationship of $A R R$ and IRR to the firm's growth in investment, $g$, was an instrumental component of Salamon's (1988) analysis of the relationship between $A R R$ and $I R R$. Previous analytical research indicated that $A R R$ and $I R R$ generally were on the same side of $g$. To determine whether this relationship could be observed in data taken from the published financial statements for a set of manufacturing firms, Salamon estimated the following model, again using $C I R R$ as a surrogate for IRR:

$$
\left|a r r_{i}-i r r_{i}\right|=\beta_{0}+\beta_{1}\left|i r r_{i}-g_{i}\right|+\varepsilon_{i},
$$

Thereafter, Salamon tested the results of previous analytical research, which suggested that the value of $\beta_{0}$ should be zero and the value of $\beta_{1}$ should be greater than 0 . Salamon's empirical results supported the latter expectation but not the former.

The current study replicates and extends Salamon's tests by using both roi and cirr as a measure of irr and testing whether the relationship described in the analytical research is observed. This process involves estimating the regression model described above and testing the following sets of hypotheses:

and

$$
\begin{aligned}
& \mathrm{H}_{\mathrm{o}} 2 \mathrm{~A}: \beta_{0}=0 \\
& \mathrm{H}_{\mathrm{a}} 2 \mathrm{~A}: \beta_{0} \neq 0
\end{aligned}
$$

$$
\mathrm{H}_{\mathrm{o}} 2 \mathrm{~B}: \beta_{1} \leq 0
$$$$
\mathrm{H}_{\mathrm{a}} 2 \mathrm{~B}: \beta_{1}>0
$$

Griner and Stark (1988) provided analytical evidence that the ratio of entity cash flows to investment in plant assets, $n c f o / g a^{+}$, is a (nearly) linear function of the firm's growth in investment, $g$, and its irr. Griner and Stark then used data from published financial reports for a sample of firms to estimate the following regression model:

$$
n c f o_{i} / g p a_{i}^{+}=\alpha_{0}+\alpha_{1} g_{i}+\alpha_{2} i r r_{i}+\varepsilon_{i}
$$

where the authors used several formulations of cirr and, for completeness, arr in place of irr. Griner and Stark's analytical results indicated that, if cirr and arr closely approximated irr, $\alpha_{1}$ would be significantly less than 0 and $\alpha_{2}$ would be significantly greater than 0 . These expectations were borne out by their empirical analyses for all formulations of cirr and arr. To replicate these analyses, the current study used the regression model developed by Griner and Stark to test the following hypotheses:

and

$$
\mathrm{H}_{\mathrm{o}} 3 \mathrm{~A}: \alpha_{1} \geq 0
$$

$$
\mathrm{H}_{\mathrm{a}} 3 \mathrm{~A}: \alpha_{1}<0
$$

$$
\begin{aligned}
& \mathrm{H}_{\mathrm{o}} 3 \mathrm{~B}: \alpha_{2} \leq 0 \\
& \mathrm{H}_{\mathrm{a}} 3 \mathrm{~B}: \alpha_{2}>0
\end{aligned}
$$

These hypotheses are formal representations of the research questions addressed in the current study. In the next section, the results of testing these hypotheses are presented. 


\section{RESULTS}

Before turning to issues addressed by Salamon (1988) and Griner and Stark (1988), the description of the results of empirical tests begins with the question of potential bias in the accounting-based profitability measures. Table 4 displays the results of Friedman tests on roi, arr, $\operatorname{cirr}_{1}, \operatorname{cirr}_{2}$, and $\operatorname{cirr}_{3}$. In its usual form, the Friedman test is a non-parametric two-way analysis of variance procedure used to test for equality of medians across dependent groups. Because the four profitability measures all are based on information about the same sample of firms, the measures are dependent. The Friedman test was performed first to control for experiment-wide error. This approach should allow greater confidence in the significance of the pair-wise comparisons that follow.

Table 4

Friedman Tests on roi, cirr $_{1}$, cirr $_{2}$, and cirr $_{3}$

\begin{tabular}{ccc}
\hline & \multicolumn{2}{c}{ F-Statistic } \\
\cline { 2 - 3 } Length of Estimation Period & Model & Profit Measure \\
\hline 5 & $1.49 * * *$ & $374.47 * * *$ \\
10 & $2.13 * * *$ & $534.21 * * *$ \\
15 & $2.62 * * *$ & $657.67 * * *$ \\
\hline
\end{tabular}

Notes: $N=4,008$. Each "Model" $F$-statistic has 1,005 numerator and 4,004 denominator degrees of freedom. Each "Profit Measure" $F$-statistic has 4 numerator and 4,004 denominator degrees of freedom. *** $p \# 0.01$ (one-tailed).

In the current study, the Friedman test was accomplished by first ranking the profit measures for each firm and then performing a two-way parametric analysis of variance using "Profit Measure" as the factor of interest and "Firm" as the blocking variable. This approach to the Friedman test for large samples is described by Conover (1980). All three of the $F$-statistics reported in Table 4 are significant at $p \# .01$, indicating that, regardless of the length of the sample period, the median value of at least one of the profitability measures is significantly different from the median values of the other profitability measures.

In order to better understand the Friedman test results, the current study then compared $a r r, \operatorname{cirr}_{1}, \operatorname{cirr}_{2}$, and cirr $_{3}$ with roi on a pair-wise basis using the Wilcoxon Signed Ranks test (Gibbons [1985]). This test compares the median values of two variables. As the results reported in Table 5 clearly indicate, the median values of arr and all formulations of cirr differed significantly from those of roi. If roi can be accepted as an adequate representation of $i r r$, both of the accounting-based profitability measures appear to be biased estimators of $i r r$.

Table 5

Wilcoxon Signed Rank Tests Among roi, arr, $\operatorname{cirr}_{1}, \mathrm{cirr}_{2}$, and $\mathrm{cirr}_{3}$

\begin{tabular}{|c|c|c|}
\hline Variable Compared With roi & $S$ Statistic & $P$-Value \\
\hline \multicolumn{3}{|c|}{ Panel A: Five-Year Estimation Period } \\
\hline$a r r$ & $-86,521$ & .0001 \\
\hline $\operatorname{cirr}_{1}$ & 241,321 & .0001 \\
\hline $\operatorname{cirr}_{2}$ & 240,316 & .0001 \\
\hline $\operatorname{cirr}_{3}$ & 239,081 & .0001 \\
\hline \multicolumn{3}{|l|}{ Panel B: Ten-Year Estimation Period } \\
\hline arr & $-223,314$ & .0001 \\
\hline $\operatorname{cirr}_{1}$ & 233,676 & .0001 \\
\hline $\mathrm{cirr}_{2}$ & 231,822 & .0001 \\
\hline $\mathrm{Cirr}_{3}$ & 219,581 & .0001 \\
\hline \multicolumn{3}{|c|}{ Panel C: Fifteen-Year Estimation Period } \\
\hline arr & $-244,332$ & .0001 \\
\hline $\operatorname{cirr}_{1}$ & 241,043 & .0001 \\
\hline $\operatorname{cirr}_{2}$ & 240,558 & .0001 \\
\hline $\mathrm{cirr}_{3}$ & 235,937 & .0001 \\
\hline
\end{tabular}

Notes: $N=1,002$. 
Although the existence of bias may be a basis for concern in some decision contexts, other decisions still may rely on accounting-based profitability measures because of their association with irr. The results of regressions using the model described by Salamon (1988) are summarized in Table 6. Diagnostic procedures described by White (1980) indicated that all of the models exhibited heteroscedasticity. As a result, $z$-statistics based on White's consistent covariance matrices are reported for each model parameter. All of the regression models are statistically significant. Analytical models suggested that the value of $\beta_{0}$ should be 0 . However, the values of $\beta_{0}$ are significant and positive in all models involving roi, regardless of the length of estimation period. In the case of models involving cirr, the values of $\beta_{0}$ range widely, indicating that the intercept depends on the formulation of cirr and length of estimation period used. Salamon's results also indicated that the intercept varied with the formulation used for cirr. As expected, $\beta_{1}$ is significant and positive in all models, regardless of whether cirr or roi is used to estimate irr. Thus, the current study confirms Salamon's finding that a significant positive association exists between arr and irr. Moreover, because the result also is obtained when roi is used as the measure of irr, greater confidence in the results reported by Salamon appears justified.

Table 6

Regression Results for:

$|a r r-i r r|=\exists_{0}+\exists_{1}|i r r-g|+\gamma$,

\begin{tabular}{cc}
\hline $\begin{array}{c}\text { Variable Used } \\
\text { for } \text { irr }\end{array}$ & $\beta_{0}$ \\
\hline $\begin{array}{c}\text { Panel A: Five-Year Estimation Period } \\
\text { roi }\end{array}$ & .002 \\
& $(2.956)^{* * *}$ \\
$\operatorname{cirr}_{1}$ & -.007 \\
& $(-3.662)^{* * *}$ \\
$\operatorname{cirr}_{2}$ & -.006 \\
$\operatorname{cirr}_{3}$ & $(-6.277)^{* * *}$ \\
& -.008 \\
& $(-10.726) * * *$
\end{tabular}

Panel B: Ten-Year Estimation Period

$\begin{array}{cc}\text { roi } & .002 \\ & (2.501)^{* *} \\ \text { cirr }_{1} & -.003 \\ & (-1.247) \\ \text { cirr }_{2} & -.000 \\ & (-.384) \\ \text { cirr }_{3} & -.002 \\ & (-2.745)^{* * *}\end{array}$

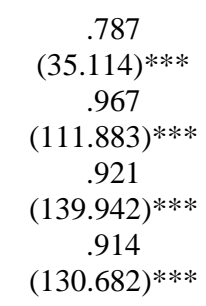

Panel C: Fifteen-Year Estimation Period

$\begin{array}{cc}\text { roi } & .004 \\ & (4.234)^{* * *} \\ \text { cirr }_{1} & .003 \\ & (1.379) \\ \text { cirr }_{2} & .003 \\ & (3.476)^{* * *} \\ \text { cirr }_{3} & .000 \\ & (.416)\end{array}$

$$
\begin{gathered}
.614 \\
(22.064) * * * \\
.968 \\
(135.357) * * * \\
.926 \\
(141.960) * * * \\
.919 \\
(123.216) * * *
\end{gathered}
$$

$F$

Statistic

$\boldsymbol{R}^{2}$

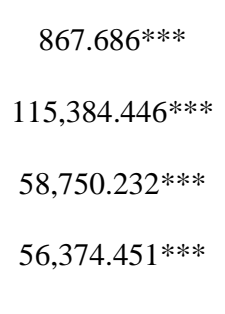

$$
1,342.669 * * *
$$$$
90,018.574 * * *
$$$$
53,133.726 * * *
$$$$
55,789.713 * * *
$$

.991

$R^{2}$

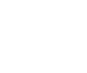


In Table 7, the results of regressions based on the model developed by Griner and Stark (1988) are summarized. Guidelines suggested by Belsley, Kuh, and Welsch (1980) did not indicate the existence of collinearity problems, but heteroscedasticity was present in these models. Therefore, $z$-statistics are reported for all model parameters. All of the models are statistically significant. The results of the current study support those reported by Griner and Stark. In all models, $\beta_{1}$ is significant and negative, and $\beta_{2}$ is significant and positive, as expected. Once again, the results for cirr indicate that the estimated model parameters depend on the length of the estimation period and the formulation of cirr used. The estimated model parameters for roi and arr appear to be more stable, and, as might be expected, the performance of roi improved somewhat as the length of the estimation period increased. The results reported in Table 7 support the test developed by Griner and Stark, and indicate that both arr and cirr have a statistically significant relationship with irr.

Table 7

Regression Results for:

$n c f o / g p a^{+}=\alpha_{0}+\alpha_{1} g+\alpha_{2} i r r+\gamma$,

\begin{tabular}{|c|c|c|c|c|c|}
\hline $\begin{array}{c}\text { Variable } \\
\text { Used for } i r r\end{array}$ & $\alpha_{0}$ & $\alpha_{1}$ & $\alpha_{2}$ & $\begin{array}{c}F \\
\text { Statistic }\end{array}$ & $R^{2}$ \\
\hline \multicolumn{6}{|c|}{ Panel A: Five-Year Estimation Period } \\
\hline roi & $\begin{array}{c}1.686 \\
(71.129)\end{array}$ & $\begin{array}{c}-29.690 \\
(-30.892)\end{array}$ & $\begin{array}{c}26.921 \\
(34.551)\end{array}$ & 606.807 & .549 \\
\hline arr & $\begin{array}{c}1.697 \\
(51.103)\end{array}$ & $\begin{array}{c}-18.748 \\
(-16.544)\end{array}$ & $\begin{array}{c}29.749 \\
(19.646)\end{array}$ & 366.242 & .423 \\
\hline $\operatorname{cirr}_{1}$ & $\begin{array}{c}1.430 \\
(21.037)\end{array}$ & $\begin{array}{c}-8.469 \\
(-10.368)\end{array}$ & $\begin{array}{c}3.413 \\
(12.457)\end{array}$ & $2,102.255$ & .808 \\
\hline $\operatorname{cirr}_{2}$ & $\begin{array}{c}1.891 \\
(31.634)\end{array}$ & $\begin{array}{c}-5.396 \\
(-4.970)\end{array}$ & $\begin{array}{c}3.466 \\
(6.024)\end{array}$ & 306.474 & .380 \\
\hline $\operatorname{cirr}_{3}$ & $\begin{array}{c}2.058 \\
(60.146)\end{array}$ & $\begin{array}{c}-3.155 \\
(-3.958)\end{array}$ & $\begin{array}{c}2.723 \\
(7.390)\end{array}$ & 132.127 & .209 \\
\hline \multicolumn{6}{|c|}{ Panel B: Ten-Year Estimation Period } \\
\hline roi & $\begin{array}{c}1.417 \\
(60.673)\end{array}$ & $\begin{array}{c}-29.128 \\
(-33.043)\end{array}$ & $\begin{array}{c}24.692 \\
(36.182)\end{array}$ & 844.717 & .628 \\
\hline arr & $\begin{array}{c}1.780 \\
(73.475)\end{array}$ & $\begin{array}{c}-17.409 \\
(-17.875)\end{array}$ & $\begin{array}{c}29.127 \\
(22.064)\end{array}$ & 495.240 & .498 \\
\hline $\operatorname{cirr}_{I}$ & $\begin{array}{c}1.400 \\
(24.528)\end{array}$ & $\begin{array}{c}-7.269 \\
(-10.507)\end{array}$ & $\begin{array}{c}3.357 \\
(12.917)\end{array}$ & $2,349.392$ & .825 \\
\hline $\operatorname{cirr}_{2}$ & $\begin{array}{c}1.796 \\
(34.703)\end{array}$ & $\begin{array}{c}-5.003 \\
(-5.011)\end{array}$ & $\begin{array}{c}3.436 \\
(6.178)\end{array}$ & 342.635 & .407 \\
\hline $\operatorname{cirr}_{3}$ & $\begin{array}{c}1.937 \\
(60.004)\end{array}$ & $\begin{array}{c}-3.120 \\
(-4.014)\end{array}$ & $\begin{array}{c}2.750 \\
(7.363)\end{array}$ & 152.527 & .234 \\
\hline \multicolumn{6}{|c|}{ Panel C: Fifteen-Year Estimation Period } \\
\hline roi & $\begin{array}{c}1.423 \\
(57.895)\end{array}$ & $\begin{array}{c}-29.943 \\
(-32.680)\end{array}$ & $\begin{array}{c}25.922 \\
(35.741)\end{array}$ & $1,007.475$ & .669 \\
\hline arr & $\begin{array}{c}1.959 \\
(76.350)\end{array}$ & $\begin{array}{c}-19.833 \\
(-17.699)\end{array}$ & $\begin{array}{c}30.121 \\
(20.122)\end{array}$ & 465.874 & .483 \\
\hline $\operatorname{cirr}_{1}$ & $\begin{array}{c}1.413 \\
(20.922)\end{array}$ & $\begin{array}{c}-9.170 \\
(-13.030)\end{array}$ & $\begin{array}{c}3.362 \\
(13.133)\end{array}$ & $2,374.037$ & .826 \\
\hline $\operatorname{cirr}_{2}$ & $\begin{array}{c}1.892 \\
(29.958)\end{array}$ & $\begin{array}{c}-6.946 \\
(-6.422)\end{array}$ & $\begin{array}{c}3.484 \\
(5.938)\end{array}$ & 316.626 & .388 \\
\hline $\operatorname{cirr}_{3}$ & $\begin{array}{c}2.068 \\
(57.517)\end{array}$ & $\begin{array}{c}-4.892 \\
(-5.787)\end{array}$ & $\begin{array}{c}2.728 \\
(7.176)\end{array}$ & 135.703 & .214 \\
\hline
\end{tabular}

Notes: $N=1,002$. For each model, the first and second rows report parameter estimates and $z$-statistics, respectively, based on White's (1980) consistent covariance matrices. Each model $F$-statistic has 2 numerator and 999 denominator degrees of freedom. All $z$-statistics and $F$-statistics are significant at $p \# 0.01$ (one-tailed). 


\section{CONCLUSION}

The inability to observe $I R R$ in actual settings has made the use of accounting-based profitability measures, such as $A R R$ and $C I R R$, necessary and frustrating. Without an observable theoretical ideal against which to evaluate the suitability of accounting-based profitability measures, researchers have had to rely on analytical and indirect empirical approaches. Both approaches have limitations that prevent them from yielding conclusive results.

The current study presented the results of a simulation approach with the intention of capturing the best attributes of both analytical and indirect empirical approaches and adding unique contributions to the literature. The experimental control of analytical research is maintained, and the need for magnitudes for understanding and testing relationships is satisfied as well. In addition, the simulation approach allows a direct measure of $I R R$ to be used as the basis for evaluating the accuracy of accounting-based profitability measures.

To demonstrate the usefulness of the simulation methodology, analyses from two recent indirect empirical studies were replicated and extended. Although the results indicate that $A R R$ and CIRR represent biased estimates of $I R R$, both accounting-based profitability measures appear to have a strong association with IRR. Moreover, the evidence of such an association resulted from two different indirect empirical approaches. The association between $A R R$ and $I R R$ appears to be more robust relative to the length of the estimation period than the relationship between $C I R R$ and IRR. Also, the strength and estimated form of the relationship between CIRR and IRR appear to depend on the formulation of CIRR used. These findings suggest that interested parties should consider the issue of stability of the relationship to $I R R$ as an important factor in selecting an accounting-based profitability measure.

\section{REFERENCES}

1. Beaver, W. H. 1979. Accounting for inflation in an efficient market. In The impact of inflation on accounting: A global view, edited by K. V. Zimmerman. Urbana, IL: The Board of Trustees of the University of Illinois.

1. Belsley, D., E. Kuh, and R. Welsch. 1980. Regression diagnostics, Identifying influential data and sources of collinearity. New York: John Wiley \& Sons.

2. Brief, R. P. 1985. Limitations of using the cash recovery rate to estimate the IRR: A note. Journal of Business Finance \& Accounting 12: 473-475.

3. Buijink, W., and M. Jegers. 1989. Accounting rates of return: Comment. American Economic Review 79: 287-289.

4. Conover, W. J. 1980. Practical nonparametric statistics. 2d ed. New York: John Wiley \& Sons.

5. Dugan, M. T., and K. A. Shriver. 1988. The importance of an environmental criterion in applied business research. Issues in Accounting Education 3: 42-47.

6. Fisher, I. 1930. The theory of interest. New York: Macmillan.

7. Fritsche, S. R., and M. T. Dugan. 1996. Bias and random measurement error in accounting-based surrogates for internal rate of return. Journal of Applied Business Research 24: 781-802.

8. Gibbons, J. D. 1985. Nonparametric methods for quantitative analysis. $2 \mathrm{~d}$ ed. Columbus, OH: American Sciences Press.

9. Griner, E. H., and A. W. Stark. 1988. Cash recovery rates, accounting rates of return and the estimation of economic performance. Journal of Accounting and Public Policy 7: 293-311.

10. Griner, E. H., and A. W. Stark. 1991. On the properties of measurement error in cash-recovery-rate-based estimates of economic performance. Journal of Accounting and Public Policy 10: 207-223.

11. Harcourt, G. C. 1965. The accountant in a golden age. Oxford Economic Papers 17: 66-80.

12. Hubbard, C. M., and R. E. Jensen. 1991. Lack of robustness and systematic bias in cash recovery rate methods of deriving internal (economic) rates of return for business firms. Journal of Accounting and Public Policy 10: 225-242.

13. Ijiri, Y. 1978. Cash flow accounting and its structure. Journal of Accounting, Auditing, and Finance 1: 341348.

14. Ijiri, Y. 1979. Convergence of cash recovery rate. In Quantitative planning and control. Edited by Y. Ijiri and A. B. Whinston. New York: Academic Press.

15. Ijiri, Y. 1980. Recovery rate and cash flow accounting. Financial Executive 48: 54-60. 
16. Jensen, R. E. 1986. The befuddled merchant of Venice: More on the "misuse" of accounting rates of return vis-à-vis economic rates of return. In Advances in public interest accounting. Vol. 1. Edited by M.

Neimark, B. Merino, and T. Tinker. New York: JAI Press.

17. Kay, J. A. 1976. The accountant, too, could be happy in a golden age: The accountant's rate of profit and the internal rate of return. Oxford Economic Papers 28: 447-460.

18. Kerlinger, F. N. 1980. Foundations of behavioral research. 3d ed. New York: Holt, Rinehart, and Winston.

19. Lee, T. A., and A. W. Stark. 1987. Ijiri's cash flow accounting and capital budgeting. Accounting and Business Research 17: 125-132.

20. Livingstone, J. L., and G. L. Salamon. 1970. Relationship between the accounting and the internal rate of return measures: A synthesis and an analysis. Journal of Accounting Research 8: 199-216.

21. Luckett, P. F. 1984. ARR vs. IRR: A review and analysis. Journal of Business Finance \& Accounting 11: 213-231.

22. Peasnell, K. V. 1996. Using accounting data to measure the economic performance of firms. Journal of Accounting and Public Policy 15: 291-303.

23. Rivett, P. 1980. Model building for decision analysis. Chichester: John Wiley \& Sons, Ltd.

24. Robert Morris Associates. 1995. Key business ratios. Philadelphia: Robert Morris Associates.

25. Salamon, G. L. 1982. Cash recovery rates and measures of firm profitability. Accounting Review 57: 292302.

26. Salamon, G. L. 1985. Accounting rates of return. American Economic Review 75: 495-504.

27. Salamon, G. L. 1988. On the validity of accounting rates of return in cross-sectional analysis: Theory, evidence, and implications. Journal of Accounting and Public Policy 7: 267-292.

28. Solomon, E. 1966. Return on investment: The relation of book-yield to true yield. In Research in accounting measurement. Edited by R. K. Jaedicke, Y. Ijiri, and O. Nielsen. Madison, WI: American Accounting Association.

29. Stark, A. W. 1989. On testing the assumptions of the cash recovery rate approach to the estimation of economic performance. Accounting and Business Research 19: 227-285.

30. Stauffer, T. R. 1971. The measurement of corporate rates of return: A generalized formulation. Bell Journal of Economics and Management Science 2: 434-469.

31. van Breda, M. F. 1981. Accounting rates of return under inflation. Sloan Management Review 22: 15-28.

32. White, H. 1980. A heteroskedasticity-consistent covariance matrix estimator and a direct test for heteroskedasticity. Econometrica 48: 817-838.

33. Whittington, G. 1979. On the use of the accounting rate of return in empirical research. Accounting and Business Research 9: 201-208.

\section{FOOTNOTES}

\footnotetext{
${ }^{1}$ The literature investigating the relationship between ARR and IRR includes contributions by Harcourt (1965), Solomon (1966), Livingstone and Salamon (1970), Stauffer (1971), van Breda (1981), Fisher and McGowan (1983), and others. Jensen (1986) and Luckett (1984) provide reviews of this literature.

${ }^{2}$ Salamon (1988) also included a definition of cirr that used a value of .8 for $b$ when the firm used an accelerated depreciation method and a value of 1.0 when the firm used the straight-line depreciation method. Because growth and depreciation method combinations were exogenously determined, this formulation would not have a meaningful interpretation and is, therefore, not included.

${ }^{3}$ Examples of studies that emphasize an equity approach to calculating $A R R$ include those by Kay (1976) and Whittington (1979).

${ }^{4}$ Alternative definitions for $C U M I N V$ were considered, several of which incorporated a randomly selected difference between the terminal book and market values of the firm's assets. These "market-based" alternative definitions were discarded for two reasons. First, because no empirical basis for assuming a particular relationship between terminal market and book values was identifiable, any definition of market value used would have been as arbitrary as the book value. Second, introducing differences between market and book values appeared to contribute little more than additional random error or bias in the statistical analyses.
} 


\section{NOTES}

